Journal of

Molecular Microbiology

\title{
Progress in Bacillus subtilis Spore Surface Display Technology towards Environment, Vaccine Development, and Biocatalysis
}

\author{
Huayou Chen ${ }^{a, b}$ Jawad Ullah ${ }^{a}$ Jinru Jia ${ }^{a}$ \\ anstitute of Life Sciences, Jiangsu University, Zhenjiang, and ${ }^{\mathrm{b}}$ National Key Laboratory of Biochemical Engineering, \\ Institute of Process Engineering, Chinese Academy of Sciences, Beijing, PR China
}

\section{Keywords}

Bacillus subtilis spores - Bioremediation - Biocatalysis .

Surface display $\cdot$ Vaccine development

\begin{abstract}
Spore surface display is the most desirable with enhanced effects, low cost, less time consuming and the most promising technology for environmental, medical, and industrial development. Spores have various applications in industry due to their ability to survive in harsh industrial processes including heat resistance, alkaline tolerance, chemical tolerance, easy recovery, and reusability. Yeast and bacteria, including gram-positive and -negative, are the most frequently used organisms for the display of various proteins (eukaryotic and prokaryotic), but unlike spores, they can rupture easily due to nutritive properties, susceptibility to heat, $\mathrm{pH}$, and chemicals. Hence, spores are the best choice to avoid these problems, and they have various applications over nonspore formers due to amenability for laboratory purposes. Various strains of Clostridium and Bacillus are spore formers, but the most suitable choice for display is Bacillus subtilis because, according to the WHO, it is safe to humans and considered as "GRAS" (generally recognized as safe). This review focuses on the application of spore surface display towards industries, vaccine development, the environment, and peptide library construction, with cell surface display for
\end{abstract}

\section{KARGER}

๑๑ 2017 S. Karger AG, Basel

E-Mail karger@karger.com

www.karger.com $/ \mathrm{mmb}$ enhanced protein expression and high enzymatic activity. Different vectors, coat proteins, and statistical analyses can be used for linker selection to obtain greater expression and high activity of the displayed protein. @ $2017 \mathrm{~S}$. Karger AG, Basel

\section{Introduction}

In extreme conditions Bacillus subtilis has the ability to enter the resting phase of sporulation and survive for a long time under harsh environmental conditions. The spores are covered by a thick peptidoglycan layer called the cortex, which is then covered by another multilayered protein coat and an outer coat layer [Henriques et al., 2004]. Thus, spores have the ability to survive in stress conditions such as high temperature, ultraviolet radiation, enzymatic and chemical damage, and desiccation. Display of proteins and peptides on the surface of microbes is becoming a fundamental tool to overcome the problems in bioprocesses, during harsh industrial processes, vaccine development, and environmental protection [Kim and Schumann, 2009]. Enzymes used for therapeutic purposes, such as lipoprotein lipase, have been broadly used to treat cardiovascular and obesity-associat-

Huayou Chen and Jawad Ullah contributed equally to this study.

Huayou Chen

Institute of Life Sciences, Jiangsu University

Zhenjiang, Jiangsu 21200 (PR China)

E-Mail hyc@ujs.edu.cn 
ed complications [Chen et al., 2016b]. Immobilization of such enzymes on the surface of $B$. subtilis spores, can lead them to be used orally for the treatment of disease and disorders. In today's developing world, whole cell biocatalysis plays a key role in industrial bioprocesses, which can be limited by solvent toxicity and low mass transfer to host cells. Surface immobilization can reduce the limitations imposed by cell membranes [Jung et al., 2006]. For successful display, the target protein needs to be fused with an anchor protein [Van Bloois et al., 2011] in order to display translocated-incompatible and multimeric proteins [Kim and Schumann, 2009] Pan et al. [2014] reported a novel concept of displaying a target protein without a fusion motif by expressing the target protein under mother cell-specific sigma-factors $\left(\sigma^{\mathrm{E}} \sigma^{\mathrm{K}}\right)$ in the last sporulation phase to absorb on the spore surface normally. This method can broaden the area for displaying those proteins and antigens on the spore surface which are unable or have difficulty to fuse with display motifs. Spores are unique structures coated with 70 different types of proteins [Setlow, 2012]. Commonly used display motifs (spore coat proteins) of B. subtilis include CotB, CotC, $\operatorname{Cot} G$, and $\operatorname{Cot} Z$, and some exosporium proteins like exosporium protease (InhA) and insecticidal protoxin (Cry1Ac) from Bacillus thuringiensis [Hinc et al., 2013; Pan et al., 2012]. For successful display, it is necessary to choose an appropriate anchor protein because they contain signal sequences for efficient promotion of transportation, immobilization, and stability to the cell surface [Tanaka et al., 2012]. The carrier protein can be fused Nor C-terminally depending upon the anchoring protein. If the anchoring protein is located on the C-terminal end, then the carrier will be on the $\mathrm{N}$-terminal side, but in cases of anchoring motifs fused $\mathrm{N}$-terminally, then the carrier will be on C-terminal side [Vida et al., 2012]. This review focuses on the applications of spore surface display systems and their importance for industry, the environment, and pharmaceuticals. We also examine their advantages in comparison to nonspore formers for overcoming problems in harsh industrial processes and easy transportation of vaccines in the natural environment due to their ability to survive in harsh conditions.

\section{Nutritive Cells}

\section{Yeast Surface Display}

Like other microorganisms (e.g., bacteria and phages), yeast is a promising tool for displaying various enzymes and proteins. Different types of enzymes are displayed and successfully immobilized on the surface of Pichia pastoris and Saccharomyces cerevisiae by fusing with the $\mathrm{N}$ terminus of the cell wall [Ren et al., 2007]. Of these, Yarrowia lipolytica, Hansenula polymorpha, Kluyveromyces lactis, and Schizosaccharomyces pombe are the most preferred organisms for protein expression and are mostly used in citric acid and isocitric acid production [Kamzolova et al., 2015]. Genetically engineered yeast has many applications in chemical synthesis, biotechnology productions, environmental pollutants adsorptions, biorefineries, and protein evolution [Tanaka et al., 2012]. Displaying costly enzymes on the surface of yeast make them costeffective and easily available for cultivation and easy recovery with excellent enzymatic characteristics for industrial application, including oil drilling and hydrolysis of coffee [Yang et al., 2009]. However, yeast surface display has certain drawbacks because of its nutritive properties, susceptibility towards heat and other harsh industrial processes, and chances of cell cracking during protein recovery when using different chemicals. The fusion of the target protein either $\mathrm{N}$ - or C-terminally is also difficult to decide and has an impact on the function of the target protein. For example, the enzymes with an active site near the C-terminus cannot be fused N-terminally because the target protein must be fused with the GPI at the C-terminus of S. cerevisiae [Boder and Wittrup, 1997].

\section{Bacterial Surface Display}

A bacterial surface display allowing recombinant proteins and peptides on the bacterial cell surface have made important contributions to the design of whole cell biocatalysis and high-throughput screening [Van Bloois et al., 2011]. Several bacterial species are used for surface display such as Lactococcus lactis, B. subtilis [Lee et al., 2003], Streptomyces coelicolor [Thompson et al., 2010], or Escherichia coli, which is the most widely used bacterial host with a variety of display systems among all these bacterial hosts. Surface display is a probable alternative for immobilized enzyme usage because it allows bacterial cell employing for effective cascade reactions for the purpose of multistep conversion, as the catalyzation of immobilized enzymes often requires transformations, which is difficult to attain by traditional chemical ways [Van Bloois et al., 2011]. For successful display and easy recovery, chimeric proteins have to cross the membrane, but some proteins lack the ability to cross the membrane barrier, thus leading to unsuccessful display [DeLisa et al., 2003]. However, using endospores for display of such proteins can lead to the success of surface display and easy recovery [Schuurmann et al., 2014].
160
J Mol Microbiol Biotechnol 2017;27:159-167 DOI: $10.1159 / 000475177$
Chen/Ullah/Jia 


\section{Display on Gram-Positive Bacteria}

Due to simple and rigid cell wall structures, gram-positive bacteria (Bacillus and Staphylococcus) strains are the most commonly used and are suitable organisms for the display of proteins on their surface as well as for whole cell biocatalysis and whole cell bioadsorbents [Lee et al., 2000]. The gram-positive bacterial cell wall (Bacillus thuringiensis) contain lysine motifs, which offer a promising approach for displaying some antimicrobial proteins and enzymes on the surface of these bacteria, for the production of heat-stable live vaccines [Liu et al., 2008]. Transmembrane proteins, LPXTG-like proteins, lipoproteins, macromolecular proteins, and cell wall-binding proteins are commonly used surface proteins for surface display [Desvaux et al., 2006]. Staphylococcus is another grampositive bacteria that has numerous approaches for expressing antibody fragments and production of immune libraries [Fleetwood et al., 2013]. Besides all these, PrsA, the molecular chaperone of $B$. subtilis [Kim et al., 2005b] and spores coat proteins are the other examples of surface display development. Most species of gram-positive bacteria are safe to human health and thus it is the most favorable choice for the display and other laboratory purposes.

\section{Display on Gram-Negative Bacteria}

Heterologous surface display is the major tool for expressing immunogens on the surface of nonpathogenic bacteria including E. coli [Narita et al., 2006] for long-lasting immune responses. For successful display in gram-negative bacteria, the anchoring motif should pass the 3 layers, i.e., the outer membrane, cytoplasmic membrane, and periplasmic spaces. Different types of proteins are used for surface display in gram-negative bacteria with different fusion strategies. Commonly used proteins for gram-negative surface display include Omp, IgA protease, INP, S-layer protein, pilin, PhoA, and flagella. The outer membrane proteins are used as carriers to display the proteins on a gramnegative surface by sandwich fusion, while INP is the most stable and is used for the display of large proteins [Lee et al., 2003]. E. coli is the most widely used gram-negative bacteria used in numerous surface displays for different purposes like vaccine development, biocatalysis, bioadsorption, and biodegradation [Lee et al., 2003]. For spore surface display of gram-negative bacteria, the most favorable is E. coli, but it needs to be confirmed whether the strain is nonpathogenic. Among all the advantages and disadvantages of both gram-positive and -negative bacteria, gram-positive bacteria are the suitable choice due to safety and spore production of some species, which make them more desirable because of heat and chemical tolerance.

Spore Surface Display

\section{Spore Surface Display (Stress Tolerance: High Temperature, pH, Organic Solvent Resistance, GRAS)}

Due to intracellular production, spores have advantages over nonspore producers because heterologously anchored proteins cannot cross any membrane. Moreover, due to the rigid spore coat, the displayed proteins and enzymes become resistant to harsh industrial processes such as high temperature, chemicals, and radiation, as well as the fact that they can be stored for a long time at room temperature [Kim and Schumann, 2009]. Spores have the ability to be reused during bioprocesses; Chen et al. [2016b] reported reusability of recombinant spores in up to 5 reaction cycles. B. subtilis spores contain different spore coat proteins, $\operatorname{Cot} \mathrm{A}, \operatorname{Cot} \mathrm{B}, \operatorname{Cot} \mathrm{C}, \operatorname{Cot} \mathrm{D}$, CotE, CotF, CotG, CotH CotJA, CotJC, CotM, CotS, CotSA, CotT, CotX, CotY,CotZ, SpoIVA, SpoVID, YabG, and YrbA [Takamatsu and Watabe, 2002], but the most preferred anchored proteins are the outer coat proteins. The most commonly used outer coat proteins are CotB [Duc le et al., 2007; Hinc et al., 2010b], CotG [Hinc et al., 2010b; Kwon et al., 2007], and CotC [Yuan et al., 2013]. In addition, an inner coat protein, $\mathrm{OxdD}$, was also used by Potot et al. [2010] for endogenous phytase exposure. The progressive way for spore surface display is presented in Figure 1.

\section{Vectors for Spore Surface Display}

For successful spore surface display, the nature of the proteins and the fusion partner's properties are the basic aspects and therefore a vector with different anchor proteins is needed. The use of different integration loci gives strength and flexibility to design different fusions on the spore surface at the same time. The C-terminal vectors Cot/CgeA genes have multiple cloning sites at the end of the gene, with no stop codon. For N-terminal vectors, however, it is located between the start codon and the remaining gene, but it needs to be verified whether the insert is cloned in the frame of the Cot gene translation and has no stop codon [Bloor and Cranenburgh, 2006]. Successful sporulation and its resistance to chloroform and lysozyme was observed when the two designed vectors (CagA protein from Helicobacter pylori, in direct association with the CgeA spore coat protein and in the other heterologous part, was connected through an $\alpha$-helical linker) were displayed on B. subtilis spores [Iwanicki et al., 2014]. The use of different vectors for spore surface display technology in different studies is presented in Table 1.

J Mol Microbiol Biotechnol 2017;27:159-167 161 


\section{Applications (Vaccine, Antigen, Antibody, Pharmaceutical Protein)}

Bacterial spores have shown some unique properties (heat resistance, $\mathrm{pH}$ stability, alkaline tolerance) and can be used for producing oral vaccines by displaying heatsensitive antigens on bacterial spores to overcome the harsh environment of the stomach [Negri et al., 2013], and they have proven to be useful in such applications. Surface-displayed recombinant spores can be used as an oral vaccine, such as expressing the tetanus toxin fragment $\mathrm{C}$ of Clostridium tetani or heat labile toxin from Escherichia coli with serum IgG titters, which were used in a mouse parental model to induce an immunogenic response and are considered for oral administration [Mauriello et al., 2004]. The efficiency of a vaccine can also be increased to some extent as with VP28, the white spot syndrome virus envelope protein, which is considered to be an effective prophylactic vaccine against white shrimp white spot syndrome and shows a slight decrease in mortality rate up to $31 \%$ after being fed VP28-displayed spore-mixed tablets [Nguyen et al., 2014]. Recombinant $B$. subtilis spores has the ability to induce systemspecific and mucosal humoral immunity, and Zhou et al. [2015] concluded higher amounts of IgG and IgA antibody titers against $H$. pylori antigen in the mice serum immunized with recombinant spores with urease $B$. subtilis spores are able to tolerate harsh environments and regrow after inactivation in most conditions. The recombinant spore in active and formaldehyde inactive forms decreased the load of TB antigen in mice in an experiment conducted by Sibley et al. [2014], and was considered to be safe for humans, easily transportable, and heat-stable mucosal vaccines. The currently available vaccine, which is either a live-attenuated or inactivated vaccine, needs to be preserved at low temperature and be used through injecting or instilling, which makes their use difficult to some extent, but by using a spore surface-displayed vaccine, all these problems can be alleviated. The spore surface-displayed vaccine can be stored at room temperature and can be mixed with animal chow for oral use in animals.

\section{Environment}

Industry plays a key role in today's developing world where gases, polluted water, and various types of hazardous chemicals and heavy metals like nickel, arsenic, chromium, and lead released from these industries have toxic effects on the health of mankind, animals, birds, and marine life. Several technologies have been developed, including precipitation-dissolution and complexation $[\mathrm{He}$ et al., 2005], to overcome these problems; however, they have not achieved wide attention due to major drawbacks such as high energy requirements and generation of hazardous sludge [Ahalya et al., 2003]. Enzymatic degradation is the best way to get rid of these problems. Nitriles used in chemical industries as intermediates are toxic and carcinogenic in nature [Gong et al., 2012], which can pollute water. To counter this, nitrilases are required to get rid of these toxic chemicals and to convert them to useful nontoxic substances such as carboxylic acid in grass. However, these grasses contain some substances (cellulose, hemicellulose, phytate) that are difficult to digest, especially for nonruminant animals such as poultry and pigs, and xylanase, hemicellulase, cellulase, protease, glycanase, or phytase which are required for digestion [Rao, 2009]. Continued monitoring is needed to overcome the problem and improve the activity of these enzymes. Immobilization is an easy and safe way to enhance and stabilize these enzymes [Chen et al., 2016a] because immobilized enzymes are capable of breaking down or disassembling pollutants repeatedly, as B. subtilis spores have the ability to regerminate and constantly display with active enzymes [Cartman et al., 2008; Nguyen, 2006]. Recombinant bacterial spores are also a bioremediation tool for heavy metals as they can absorb these and recover them from the ecosystem, like absorption and recovery of nickel ions using B. subtilis spores [Hinc et al., 2010a]. Due to absorptive properties of recombinant spores, surface display of different enzymes on B. subtilis spores is becoming a fundamental tool for bioremediation processes as it has a major advantage over conventional methods including a revival of absorbed material, good efficacy, and low cost.

\section{Enzyme Immobilization/Biocatalysis (Industrial Enzymes under a Harsh or Bad Environment)}

Displaying different proteins on B. subtilis spores has great potential for applications in protein immobilization. Display of proteins on spore surfaces may result in changes in protein structure and surface charges leading to increase in relative activity, thermostability, $\mathrm{pH}$ stability, and reusability [Chen et al., 2016a]. For example, an increase of $18 \%$ in the retained activity [Chen et al., 2015b], 30-40\% in thermostability and $\mathrm{pH}$ stability [Chen et al., 2015a], and 83\% in reusability [Chen et al., 2016a],
162

J Mol Microbiol Biotechnol 2017;27:159-167 DOI: $10.1159 / 000475177$
Chen/Ullah/Jia 


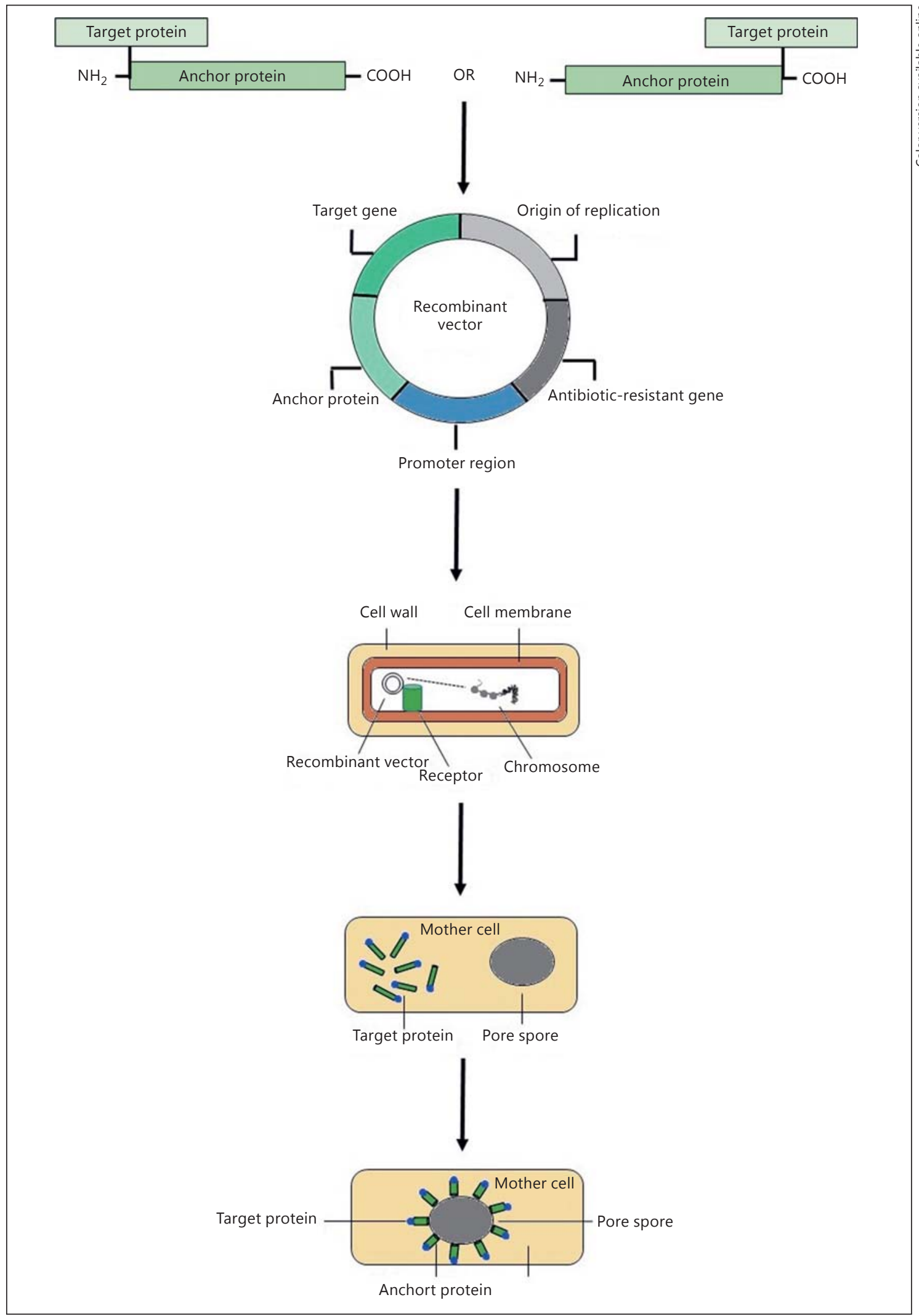

Fig. 1. Construction of fusion protein $\mathrm{N}$ - or C-terminal and process of spore displaying target protein on their surface. 
Table 1. List of fusion and target proteins, used vectors, and application of Bacillus subtilis spore surface-displayed proteins

\begin{tabular}{|c|c|c|c|c|c|}
\hline Bacterial strain & Fusion protein & Target protein & Used vector & Applications & Reference \\
\hline B. subtilis PY79 (Spo+) & CotC & TTFC and LTB & $\begin{array}{l}\text { pRH22 and } \\
\text { pIM51 }\end{array}$ & $\begin{array}{l}\text { Clostridium tetani and } \\
\text { E. coli vaccine }\end{array}$ & Mauriello et al., 2004 \\
\hline B. subtilis 168 & $\begin{array}{l}\text { CotB, CotC, } \\
\text { CotG, and } \operatorname{Cot} Z\end{array}$ & FliD & $\mathrm{pDL}$ & C. difficile oral vaccines & Negri et al., 2013 \\
\hline B. subtilis WB600 & CotC & urease B & pUS186 & Oral vaccine for $H$. pylori & Zhou et al., 2015 \\
\hline B. subtilis HU58 & CotB & MPT64 & pcotVac & Vaccine against tuberculosis & Sibley et al., 2014 \\
\hline B. subtilis PY79 & CotB & RSM2e3 & pDG1664 & Influenza vaccine & Zhao et al., 2014 \\
\hline B. subtilis & CotC & Pep23 & pDG364 & CD4 T-cell-based vaccine & D’Apice et al., 2007 \\
\hline B. subtilis PY79 & CotB and CotC & PA & pDG364 & Vaccine against anthrax & Duc le et al., 2007 \\
\hline B. subtilis 168 trpC2 & CotB & CTB-OVA epi & pHY300 & Cholera vaccine & $\begin{array}{l}\text { Han and Enomoto, } \\
2010\end{array}$ \\
\hline B. subtilis PY79 & CotB & GST-Cpa247-370 & pDL243 & $\begin{array}{l}\text { Vaccine against necrotic } \\
\text { enteritis }\end{array}$ & Hoang et al., 2008 \\
\hline B. subtilis WB600 & CotC & CsTP22.3 & pUS186 & Vaccine against Clonorchis sinensis & Zhou et al., 2008 \\
\hline B. subtilis DB104 & CotG & Streptavidin & pHPS9 & Diagnosis & Kim et al., 2005a \\
\hline B. subtilis DB104 & CotG & GFPUV & pCSK1 & Diagnosis & Kim et al., 2006 \\
\hline B. subtilis $168(\operatorname{trp}-)$ & CotC & HSA & pJS700 & Increased serum albumin & Mao et al., 2012 \\
\hline B. subtilis PY79 & CotB & VP28 & pDG364 & Vaccine for shrimps & Nguyen et al., 2014 \\
\hline B. subtilis PY79 and RH201 & CotB & Histidine & pDHAFB & Bioremediation & Hinc et al., 2010a \\
\hline B. subtilis DB104 & CotG & $\omega$-Transaminase & pCSK1 & Industrial biocatalysis & Hwang et al., 2011 \\
\hline B. subtilis DB403 & CotB & DSM & pHS & Industrial biocatalysis & Chen et al., 2015b \\
\hline B. subtilis DB104 & prsA & celA & pUB18-P43-SP & Industrial biocatalysis & Kim et al., 2005b \\
\hline B. subtilis PY79 & OxdD and CotG & phytase & pDG364 & $\begin{array}{l}\text { Industrial biocatalysis and } \\
\text { animal probiosis }\end{array}$ & Potot et al., 2010 \\
\hline B. subtilis DB403 & CotB & Tm1350 & pHS & Industrial biocatalysis & Chen et al., 2015a \\
\hline B. subtilis PY79 & $\begin{array}{l}\text { CotB, Cot } C \text {, and } \\
\operatorname{Cot} G\end{array}$ & ureA & pGEM and $\mathrm{pDL}$ & Industrial biocatalysis & Hinc et al., 2010b \\
\hline B. subtilis 168 (trp-) & CotC & $\operatorname{adhA}$ & pJS700 & Industrial biocatalysis & Yuan et al., 2013 \\
\hline B. subtilis DB403 & CotG & nit & pHS & Industrial biocatalysis & Chen et al., 2016a \\
\hline B. subtilis WB600 & CotG & Neu5Ac aldolase & pEB03 & Industrial biocatalysis & Gao et al., 2011 \\
\hline B. subtilis 168 (trp-) & CotC & $\mathrm{BmADH}$ & pJS700 & Industrial biocatalysis & Wang et al., 2011 \\
\hline B. subtilis DB104 & Cot $\mathrm{G}$ & $\beta-G a l$ & pDG1728 & Industrial biocatalysis & Kwon et al., 2007 \\
\hline
\end{tabular}

respectively, was noted in immobilized surface-displayed esterases other than nonimmobilized ones. Biocatalysis, a powerful technique used in biochemical industries, is a one-step process that results in low-cost productivity [Schoemaker et al., 2003]. During biocatalytic reactions, enzymes are inactivated and they need to immobilize and enhance thermostability and tolerance to organic chemicals and $\mathrm{pH}$ [Hailes et al., 2007]. Displaying environment-susceptible enzymes and other biocatalysts on the spore surface enhances productivity rate, $\mathrm{pH}$ stability, thermostability, and survival in harsh conditions by forming robust spores [Gao et al., 2011; Wang et al., 2011]. Thus, the spore surface-displayed enzymes and biocatalysis might be a way to produce cost-effective chemoenzymatic compounds. Feasible enzymes are not appropriate for industrial purposes because of the increase and decrease of temperature and $\mathrm{pH}$ during industrial processes which can affect the activity and stability of feasible enzymes, hence the need to use strong enzymes and spores to tolerate harsh industrial environments.

\section{Peptide Libraries}

The fusion of a carrier protein with an anchoring protein has a direct impact on successful surface display as well as on the activity and stability of the displayed protein. It is difficult to predict whether the peptide sequence (linkers) is helpful for increasing the stability and activity of proteins, but our unpublished data suggest numerous effects on enzyme activity and stability using different peptide linkers than direct linking with an anchor protein. The UreA subunit from $H$. acinonychis showed improved expression when the peptide linker GGGEAAAKGGG was used rather than EAAAK, but failed to express when GGGGS was used [Hinc et al., 2013]. When using peptide linkers with different amino acid sequences, orientation and length is the best way to enhance the expression of proteins with different properties such as increased activity, stability, alkaline tolerance, and heat resistance. By using different suitable linkers with various properties, which can be done using statistical analysis 
like the response surface methodology, peptide libraries can be made for certain proteins with the best expression properties.

\section{Limitations}

Spore surface display has numerous applications in industries and environmental and medical science, but there are certain limitations which make it difficult to get the desired results. The success of display on the surface of spores depends on the fusion of anchored and target proteins, so it becomes harder to choose the correct fusion and anchor partner. Hinc et al. [2010b] reported expression failure of UreA from $H$. acinonychis when displayed with $\operatorname{Cot} B$ and $\operatorname{Cot} C$ as the carrier, but succeeded when displayed using CotG. Similarly, Iwanicki et al. [2014] reported the failure of surface display when using a flexible linker GGGGS between CotZ and UreA, but achieved promising results when a rigid linker (EAAAK) was used. So it always difficult to select the right vector and anchor protein for the specific gene, and more effort is needed to get the right choice. Moreover, the use of the right or no linker is also difficult because in most cases the use of a linker makes the target protein more stable than not using one.

\section{Conclusion and Future Perspectives}

Due to low cost and auspicious applications, display of proteins and peptides on microorganisms is becoming a leading technology. Microorganisms (bacteria, yeast, and phages) are used for the display of these proteins. Spore surface display is a multimeric strategy for the production of vaccines, as well as certain applications to industrial biocatalysis and environment protection. Using different proteins and antigens on the spore surface can enhance their activity and stability for biodegradation of hazardous compounds, and can have relevance for vaccine approaches. For a successful display, chimeric proteins have to cross at least one membrane; however, some proteins do not have the ability to cross because of fast folding and hydrophobic patches. To avoid all these problems, the best way is to use endospore-forming bacteria like $B$. subtilis because the proteins displayed on the spore surface do not need to cross the membrane barrier. For the extraction of required proteins, nutritive cells need special chemical treatment or ultrasonic waves to disrupt the cell to obtain the required protein, while the

Spore Surface Display proteins linked to the spore surface can be separated easily and the product by centrifugation. Nutritive cells including bacteria are susceptible to environmental stress and can be disrupted easily, hence there is a chance of wasting desired proteins while spores have the ability to survive in unfavorable conditions. Displaying enzymes on the surface of yeast is more time consuming, about $96 \mathrm{~h}$ for reaching the highest activity, but the time is limited for the spores and reach the maximum activity level at less than $48 \mathrm{~h}$.

To enhance the enzymatic activity, we need to study the molecular dynamics of the desired protein and design a suitable linker for fusion protein construction. A relative flexible linker between the carrier and target protein is the better choice for relative free movement of the C- or N-terminal to get a more optimized structural domain. A rigid linker can maintain a certain distance in the two domains so as to avoid interference. Therefore, it is very important to find a suitable linker for surface display on the spores. A linker library should be built up using statistical methods to analyze the effect on folding of the enzyme space structure by the interaction of single factor or more factors concerning different length, flexibility, constituent, hydrophobicity, charge property, sequence of amino acid residues, secondary structure, and to gain a better understanding of the influence of enzyme activity and stress resistance ability. The preliminary spore display model should be set up for linker design and the guiding principle of efficiency and inexpensive immobilization of the industrial enzyme. A multienzyme complex is a large molecular structure formed by noncovalent bonds of enzymes. Displaying enzymes on the spore surface able to form the multienzyme complex is a new way to solve the expression and immobilization of the multienzyme complex. An experimental strategy is to link different enzymes of the multienzyme complex with different coat proteins, and codisplay them on the surface of the spores at the same time. For the large expression of fusion proteins, different expression vectors can be used, but it is better to select the strain for the desired enzyme which has a close relationship to B. subtilis, which is a gram-positive bacterium. Spore coat protein CotB is a low abundance protein. Sometimes it is unable to express the desired proteins to improve the enzyme expression level, so another anchor protein or varieties of spore coat proteins such as $(\operatorname{Cot} G, \operatorname{Cot} C, \operatorname{Cot} X)$ would be selected to immobilize the enzyme.

J Mol Microbiol Biotechnol 2017;27:159-167 DOI: $10.1159 / 000475177$ 


\section{Acknowledgment}

This work was supported by the National Key Basic Research Program of China (973 Program, No. 2011CBA00800), the Open Funding Project of National Key Laboratory of Biochemical Engineering, and the Key Agriculture Support Project of Jiangsu Province, PR China (No. BE2013400).

\section{Disclosure Statement}

All the authors read approve the manuscript and declared no competing interests exist.

\section{References}

Ahalya N, Ramachandra TV, Kanamadi RD: Biosorption of heavy metals. Res J Chem Environ 2003;7:71-80.

Bloor AE, Cranenburgh RM: An efficient method of selectable marker gene excision by Xer recombination for gene replacement in bacterial chromosomes. Appl Environ Microbiol 2006;72:2520-2525.

Boder ET, Wittrup KD: Yeast surface display for screening combinatorial polypeptide libraries. Nat Biotechnol 1997;15:553-557.

Cartman ST, La Ragione RM, Woodward MJ: Bacillus subtilis spores germinate in the chicken gastrointestinal tract. Appl Environ Microbiol 2008;74:5254-5258.

Chen H, Chen Z, Ni Z, Tian R, Zhang T, Jia J, Chen K, Yang S: Display of Thermotoga maritima MSB8 nitrilase on the spore surface of Bacillus subtilis using out coat protein CotG as the fusion partner. J Mol Catal B Enzym 2016a;123:73-80.

Chen H, Jia J, Ni Z, Vastermark A, Wu B, Le Y, Jawad U: Orlistat response to missense mutations in lipoprotein lipase. Biotechnol Appl Biochem 2016b, DOI: 10.1002/bab.1500.

Chen H, Tian R, Ni Z, Zhang Q, Zhang T, Chen Z, Chen K, Yang S: Surface display of the thermophilic lipase Tm1350 on the spore of Bacillus subtilis by the CotB anchor protein. Extremophiles 2015a;19:799-808.

Chen H, Zhang T, Jia J, Vastermark A, Tian R, Ni Z, Chen Z, Chen K, Yang S: Expression and display of a novel thermostable esterase from Clostridium thermocellum on the surface of Bacillus subtilis using the CotB anchor protein. J Ind Microbiol Biotechnol 2015b;42: 1439-1448.

D’Apice L, Sartorius R, Caivano A, Mascolo D, Del Pozzo G, Di Mase DS, Ricca E, Li Pira G, Manca F, Malanga D, De Palma R, De Berardinis P: Comparative analysis of new innovative vaccine formulations based on the use of procaryotic display systems. Vaccine 2007;25: 1993-2000.

DeLisa MP, Tullman D, Georgiou G: Folding quality control in the export of proteins by the bacterial twin-arginine translocation pathway. Proc Natl Acad Sci USA 2003;100:61156120.

Desvaux M, Dumas E, Chafsey I, Hebraud M: Protein cell surface display in Gram-positive bacteria: from single protein to macromolecular protein structure. FEMS Microbiol Lett 2006;256:1-15.
Duc le H, Hong HA, Atkins HS, Flick-Smith HC, Durrani Z, Rijpkema S, Titball RW, Cutting SM: Immunization against anthrax using $\mathrm{Ba}$ cillus subtilis spores expressing the anthrax protective antigen. Vaccine 2007;25:346-355. Fleetwood F, Devoogdt N, Pellis M, Wernery U, Muyldermans S, Stahl S, Lofblom J: Surface display of a single-domain antibody library on Gram-positive bacteria. Cell Mol Life Sci 2013;70:1081-1093.

Gao C, Xu X, Zhang X, Che B, Ma C, Qiu J, Tao $\mathrm{F}, \mathrm{Xu}$ P: Chemoenzymatic synthesis of $\mathrm{N}$-acetyl-D-neuraminic acid from $\mathrm{N}$-acetyl-D-glucosamine by using the spore surface-displayed N-acetyl-D-neuraminic acid aldolase. Appl Environ Microbiol 2011;77:7080-7083.

Gong JS, Lu ZM, Li H, Shi JS, Zhou ZM, Xu ZH: Nitrilases in nitrile biocatalysis: recent progress and forthcoming research. Microb Cell Fact 2012;11:387-390.

Hailes HC, Dalby PA, Woodley JM: Integration of biocatalytic conversions into chemical syntheses. J Chem Technol Biotechnol 2007;82: 1063-1066

Han M, Enomoto K: Surface display of recombinant protein on the cell surface of Bacillus subtilis by the CotB anchor protein. World J Microbiol Biotechnol 2010;27:719-726.

He ZL, Yang XE, Stoffella PJ: Trace elements in agroecosystems and impacts on the environment. J Trace Elem Med Biol 2005;19:125140.

Henriques AO, Costa T, Martins LO, Zilhao R: Functional architecture and assembly of the spore coat; in Ricca E, Henriques AO, Cutting SM (eds): Bacterial Spore Formers: Probiotics and Emerging Applications. London, Horizon Science Press, 2004, pp 34-52.

Hinc K, Ghandili S, Karbalaee G, Shali A, Noghabi KA, Ricca E, Ahmadian G: Efficient binding of nickel ions to recombinant Bacillus subtilis spores. Res Microbiol 2010a;161:757764.

Hinc K, Isticato R, Dembek M, Karczewska J, Iwanicki A, Peszynska-Sularz G, De Felice M, Obuchowski M, Ricca E: Expression and display of UreA of Helicobacter acinonychis on the surface of Bacillus subtilis spores. Microb Cell Fact 2010b;9:2.

Hinc K, Iwanicki A, Obuchowski M: New stable anchor protein and peptide linker suitable for successful spore surface display in B. subtilis. Microb Cell Fact 2013;12:22.
Hoang TH, Hong HA, Clark GC, Titball RW, Cutting SM: Recombinant Bacillus subtilis expressing the Clostridium perfringens alpha toxoid is a candidate orally delivered vaccine against necrotic enteritis. Infect Immun 2008; 76:5257-5265.

Hwang BY, Kim BG, Kim JH: Bacterial surface display of a co-factor containing enzyme, omega-transaminase from Vibrio fluvialis using the Bacillus subtilis spore display system. Biosci Biotechnol Biochem 2011;75:18621865.

Iwanicki A, Piątek I, Stasiłojć M, Grela A, Lęga T, Obuchowski M, Hinc K: A system of vectors for Bacillus subtilis spore surface display. Microb Cell Fact 2014;13:30.

Jung HC, Kwon SJ, Pan JG: Display of a thermostable lipase on the surface of a solvent-resistant bacterium, Pseudomonas putida GM730, and its applications in whole-cell biocatalysis. BMC Biotechnol 2006;6:23.

Kamzolova SV, Lunina YN, Allayarov RK, Puntus IF, Laptev IA, Samoilenko VA, Morgunov IG: Biosynthesis of isocitric acid by the yeast Yarrowia lipolytica and its regulation. Appl Biochem Microbiol 2015;51:249-254.

Kim J, Schumann W: Display of proteins on Bacillus subtilis endospores. Cell Mol Life Sci 2009; 66:3127-3136.

Kim JH, Changhyun R, Chang WL, Dohyun K, Soo KC, Heung CJ, Jae GP, Byung GK: Bacterial surface display of GFPUV on Bacillus subtilis spores. J Microbiol Biotechnol 2006;17: 677-680.

Kim JH, Lee CS, Kim BG: Spore-displayed streptavidin: a live diagnostic tool in biotechnology. Biochem Biophys Res Commun 2005a;331: 210-214.

Kim JH, Park IS, Kim BG: Development and characterization of membrane surface display system using molecular chaperon, prsA, of Bacillus subtilis. Biochem Biophys Res Commun 2005b;334:1248-1253.

Kwon SJ, Jung HC, Pan JG: Transgalactosylation in a water-solvent biphasic reaction system with beta-galactosidase displayed on the surfaces of Bacillus subtilis spores. Appl Environ Microbiol 2007;73:2251-2256.

Lee JS, Shin KS, Pan JG, Kim CJ: Surface-displayed viral antigens on Salmonella carrier vaccine. Nat Biotechnol 2000;18:645-648.

Lee SY, Choi JH, Xu Z: Microbial cell-surface display. Trends Biotechnol 2003;21:45-52. 
Liu M, Li S, Hu S, Zhao C, Bi D, Sun M: Display of avian influenza virus nucleoprotein on $\mathrm{Ba}$ cillus thuringiensis cell surface using CTC as a fusion partner. Appl Microbiol Biotechnol 2008;78:669-676.

Mao L, Jiang S, Li G, He Y, Chen L, Yao Q, Chen $\mathrm{K}$ : Surface display of human serum albumin on Bacillus subtilis spores for oral administration. Curr Microbiol 2012;64:545-551.

Mauriello EM, Duc le H, Isticato R, Cangiano G, Hong HA, De Felice M, Ricca E, Cutting SM: Display of heterologous antigens on the Bacillus subtilis spore coat using CotC as a fusion partner. Vaccine 2004;22:1177-1187.

Narita J, Okano K, Tateno T, Tanino T, Sewaki T, Sung MH, Fukuda H, Kondo A: Display of active enzymes on the cell surface of Escherichia coli using PgsA anchor protein and their application to bioconversion. Appl Microbiol Biotechnol 2006;70:564-572.

Negri A, Potocki W, Iwanicki A, Obuchowski M, Hinc K: Expression and display of Clostridium difficile protein FliD on the surface of $\mathrm{Ba}$ cillus subtilis spores. J Med Microbiol 2013;62: 1379-1385.

Nguyen AT, Pham CK, Pham HT, Pham HL, Nguyen AH, Dang LT, Huynh HA, Cutting SM, Phan TN: Bacillus subtilis spores expressing the VP28 antigen: a potential oral treatment to protect Litopenaeus vannamei against white spot syndrome. FEMS Microbiol Lett 2014;358:202-208.

Nguyen KMT, Nguyen QU, Huynh AH, Duc LH, Tran TH, Serra CR, Henriques AO, Cutting SM: The intestinal life cycle of Bacillus subtilis and close relatives. J Bacteriol 2006;188: 2692-2700.

Pan JG, Choi SK, Jung HC, Kim EJ: Display of native proteins on Bacillus subtilis spores. FEMS Microbiol Lett 2014;358:209-217.

Pan JG, Kim EJ, Yun CH: Bacillus spore display. Trends Biotechnol 2012;30:610-612.
Potot S, Serra CR, Henriques AO, Schyns G: Display of recombinant proteins on Bacillus subtilis spores, using a coat-associated enzyme as the carrier. Appl Environ Microbiol 2010;76: 5926-5933.

Rao DE, Rao KV, Reddy TP, Reddy VD: Molecular characterization, physicochemical properties, known and potential application of phytases: an overview. Crit Rev Biotechnol 2009; 29:192-198.

Ren R, Jiang Z, Liu M, Tao X, Ma Y, Wei D: Display of adenoregulin with a novel Pichia pastoris cell surface display system. Mol Biotechnol 2007;35:103-108.

Schoemaker HE, Mink D, Wubbolts MG: Dispelling the myths - biocatalysis in industrial synthesis. Science 2003;299:1694-1697.

Schuurmann J, Quehl P, Festel G, Jose J: Bacterial whole-cell biocatalysts by surface display of enzymes: toward industrial application. Appl Microbiol Biotechnol 2014;98:8031-8046.

Setlow P: Dynamics of the assembly of a complex macromolecular structure - the coat of spores of the bacterium Bacillus subtilis. Mol Microbiol 2012;83:241-244.

Sibley L, Reljic R, Radford DS, Huang JM, Hong HA, Cranenburgh RM, Cutting SM: Recombinant Bacillus subtilis spores expressing MPT64 evaluated as a vaccine against tuberculosis in the murine model. FEMS Microbiol Lett 2014;358:170-179.

Takamatsu H, Watabe K: Assembly and genetics of spore protective structures. Cell Mol Life Sci 2002;59:434-444.

Tanaka T, Yamada R, Ogino C, Kondo A: Recent developments in yeast cell surface display toward extended applications in biotechnology. Appl Microbiol Biotechnol 2012;95:577-591.

Thompson BJ, Widdick DA, Hicks MG, Chandra G, Sutcliffe IC, Palmer T, Hutchings MI: Investigating lipoprotein biogenesis and function in the model Gram-positive bacterium Streptomyces coelicolor. Mol Microbiol 2010; 77:943-957.
Van Bloois E, Winter RT, Kolmar H, Fraaije MW: Decorating microbes: surface display of proteins on Escherichia coli. Trends Biotechnol 2011;29:79-86.

Vida T, Ibrahim T, Mohsen D, Gholamreza A: Microbial cell surface display; its medical and environmental application. Iran J Biotechnol 2012;10:231-239.

Wang N, Chang C, Yao Q, Li G, Qin L, Chen L, Chen K: Display of Bombyx mori alcohol dehydrogenases on the Bacillus subtilis spore surface to enhance enzymatic activity under adverse conditions. PLoS One 2011;6:e21454.

Yang XS, Jiang ZB, Song HT, Jiang SJ, Madzak C, Ma LX: Cell-surface display of the active mannanase in Yarrowia lipolytica with a novel surface-display system. Biotechnol Appl Biochem 2009;54:171-176.

Yuan Y, Feng F, Chen L, Yao Q, Chen K: Surface display of Acetobacter pasteurianus AdhA on Bacillus subtilis spores to enhance ethanol tolerance for liquor industrial potential. Eur Food Res Technol 2013;238:285-293.

Zhao G, Miao Y, Guo Y, Qiu H, Sun S, Kou Z, Yu H, Li J, Chen Y, Jiang S, Du L, Zhou Y: Development of a heat-stable and orally delivered recombinant M2e-expressing B. subtilis spore-based influenza vaccine. Hum Vaccin Immunother 2014;10:3649-3658.

Zhou Z, Gong S, Li XM, Yang Y, Guan R, Zhou S, Yao S, Xie Y, Ou Z, Zhao J, Liu Z: Expression of Helicobacter pylori urease B on the surface of Bacillus subtilis spores. J Med Microbiol 2015;64:104-110.

Zhou Z, Xia H, Hu X, Huang Y, Li Y, Li L, Ma C, Chen X, Hu F, Xu J, Lu F, Wu Z, Yu X: Oral administration of a Bacillus subtilis sporebased vaccine expressing Clonorchis sinensis tegumental protein $22.3 \mathrm{kDa}$ confers protection against Clonorchis sinensis. Vaccine 2008;26:1817-1825. 